\title{
ИСПОЛЬЗОВАНИЕ ИНДЕКСА РЕЗИСТИВНОСТИ ДЛЯ ОЦЕНКИ СТАДИИ ХРОНИЧЕСКОЙ БОЛЕЗНИ ПОЧЕК У БОЛЬНЫХ САХАРНЫМ ДИАБЕТОМ 2 ТИПА
}

\author{
Нагибович О.А., Шипилова Д.А. \\ ФГБВОУ ВО «Военно-медицинская академия им. С.М. Кирова» Министерства обороны Российской Федерации, \\ Санкт-Петербург
}

ЦЕЛЬ: определить диагностическую значимость индекса резистивности (RI) для оценки стадии хронической болезни почек (ХБП) у больных сахарным диабетом (СД) 2 типа.

МЕТОДЫ: обследовано 48 больных СД 2 типа, осложненным ХБП 1-4 стадиями с уровнем экскреции альбумина с мочой А1, в возрасте от 53 до 67 лет. Пациенты были распределены на две группы: 1-ю группу составили 25 пациентов (18 мужчин и 7 женщин) в возрасте от 53 до 63 лет с продолжительностью СД от 5 до 15 лет, уровнем гликированного гемоглобина от 7,9 до 10,1\%, уровнем альбумин-креатининового (A/Kр) соотношения от 0,7 до 2,8 мг/ммоль, у которых определялась скорость клубочковой фильтрации (СКФ) выше или равная 60 мл/мин/1,73м²; 2-ю группу составили 23 больных (17 мужчин и 6 женщин) в возрасте от 54 до 65 лет с продолжительностью СД от 7 до 16 лет, уровнем гликированного гемоглобина от 8,7 до 10,6\%, уровнем А/Кр соотношения от 0,6 до 1,3 мг/ммоль, у которых определялась СКФ ниже 60 мл/мин/1,73м². Диагноз ХБП устанавливали на основании определения CKФ по формуле CKD-EPI и определения A/Kр в соответствии с рекомендациями международного общества нефрологов KDIGO. Всем пациентам было выполнено ультразвуковое допплерографическое исследование одной из сегментарных артерий правой почки на ультразвуковом аппарате SONOLINE OMNIA (SIEMENS, Германия) датчиком C 5-2 МГц. Определяли показатель внутрипочечного сосудистого сопротивления: RI. Статистическая обработка полученных результатов исследования проводилась с использованием программы Statistica 10, IBM SPSS Statistics 23, MedCalc (версия 18.11.3). Для определения диагностической значимости теста рассчитывали: диагностическую точку отсечения, чувствительность, специфичность, прогностическую ценность положительного результата (ПЦПР), прогностическую ценность отрицательного результата (ПЦОР), отношение правдоподобия положительного результата теста (ОППРТ), отношение правдоподобия отрицательного результата теста (ОПОРТ), эффективность (точность распознавания), значения площади под ROC-кривой.

PЕзУЛЬТАТЫ: в общей группе наблюдалась взаимосвязь между RI и: креатинином сыворотки ( $\rho=0,38$, $p=0,002)$, CKФ ( $\rho=-0,43, p=0,002)$. В ходе ROC-анализа на уровне правой сегментарной артерии было установлено пороговое значение для показателя $\mathrm{RI} \approx 0,7$, которое соответствовало наличию стадии ХБП С3.

При этом чувствительность данного диагностического теста составила 87,50\%, ПЦПР=91,30\%, ПЦОР=80,00\%, ОППРТ=6,12, ОПОРТ=0,15 специфичность 85,71\%, эффективность 86,84\%. Площадь под ROC-кривой составила 0,897.

ВЫвОды: полученные данные свидетельствуют о возможности использования индекса резистивности для неинвазивной оценки развития хронической болезни почек третьей и более продвинутых стадий у больных сахарным диабетом 2 типа. 